\title{
Hybrid Treatment of Multilevel Aortic Disease in an Adolescent: A Case Report
}

Giselle Rowlinson*, Darryl F Shore, Maziar Mireskandari, Nick J Cheshire, Michael Rigby and Inga Voges*

Royal Brompton and Harefield NHS Foundation Trust, Sydney Street, London, UK

\begin{abstract}
Bicuspid aortic valve is a common congenital defect associated with several other pathological processes. We describe a complex case in a 13-year-old boy where there was significant aortic valve insufficiency and a severely dilated ascending aorta. In addition, there was complex coarctation of the aorta in which both subclavian arteries arose from the coarctation site. A hybrid bilateral carotid-subclavian bypass grafting with coarctation stenting procedure was performed followed by a modified Bentall procedure. This case illustrates a successful two-stage, hybrid technique in a late-diagnosed paediatric patient.
\end{abstract}

Keywords: Bicuspid aortic valve; Coarctation; Anomalous right subclavian artery; Stent; Bentall procedure

\section{Introduction}

Bicuspid aortic valve occurs in $1 \%$ to $2 \%$ of the population, is associated with aortopathy, and commonly coexists with coarctation of the aorta [1]. Once bicuspid aortic valve is diagnosed, regular review would ensure timely intervention either for progression of valvar insufficiency or for progressive aortic root or ascending aorta dilatation [2]. The Bentall procedure is an established technique in children $[3,4]$ and adults to replace the ascending aorta $[5,6]$ in the presence of abnormal valve function. Coarctation of the aorta is commonly diagnosed in infancy during which time surgical repair would usually be indicated, however in adulthood endovascular stenting is becoming the first intervention of choice in uncomplicated cases [7].

\section{Case Report}

A 13 year old boy presented with an 18 month history of nausea most mornings and intermittent bouts of morning vomiting every few months. He also complained of exercise intolerance, chest pains on maximal exertion and shortness of breath which had been managed with inhalers. Clinical examination revealed a right arm blood pressure of 130/85 mmHg (mean $95 \mathrm{mmHg}$ ) and impalpable femoral pulses. His cardiac apex was displaced and both ejection systolic and early diastolic

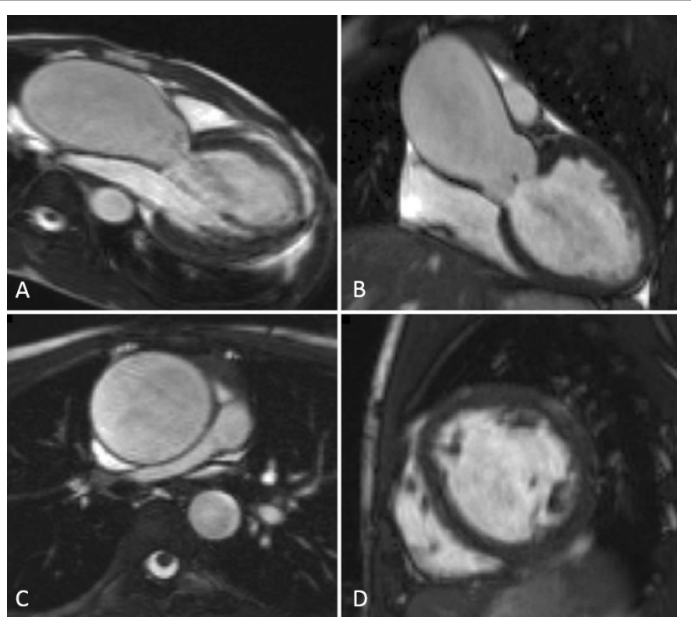

Figure 1: (A-C) Cardiovascular magnetic resonance (CMR) cine images showing severe dilatation of the ascending aorta and dilatation of the aortic root with aortic regurgitation Dilated left ventricle. (D). With mildly impaired ejection fraction (LVEF 54\%).

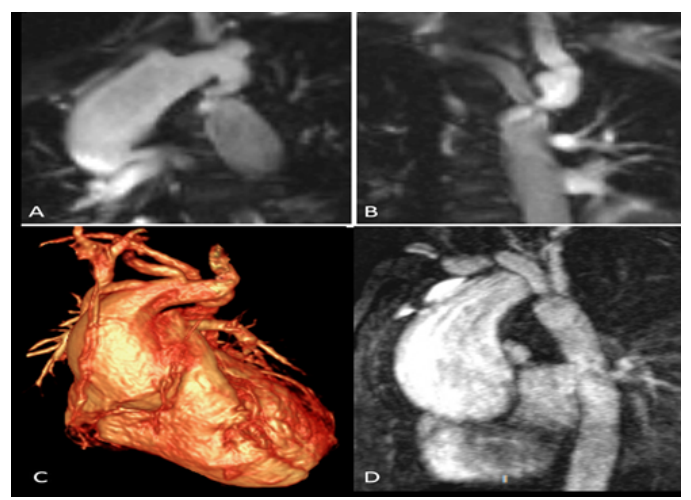

Figure 2: (A-C) CMR cine images, volume-rendered 3D reconstruction and maximum intensity projection showing a tortuous aortic arch and severe narrowing at the aortic isthmus. (B, D). Anomalous origin of the right subclavian artery arising together with the left subclavian artery at the level of the coarctation.

murmurs were audible. ECG showed left ventricular hypertrophy and chest X-ray showed an abnormal aortic arch contour. Echocardiography demonstrated a bicuspid aortic valve with moderate regurgitation. The left ventricle was dilated with impaired systolic function (ejection fraction 45\%). The aortic root and ascending aorta were severely dilated (ascending aorta $6 \mathrm{~cm}$ ). There was severe coarctation of the aorta (minimum aortic diameter $3 \mathrm{~mm}$ ) with a maximum velocity through the coarctation site of $4 \mathrm{~m} / \mathrm{s}$. Cardiovascular magnetic resonance imaging (CMR) confirmed the diagnosis showing a bicuspid aortic valve with moderate aortic regurgitation (regurgitant fraction $24 \%$ ) and severe ascending aortic dilatation ascending aorta $5.8 \times 6 \mathrm{~cm}$; Figures 1A-1C). The left ventricle was dilated with impaired ejection fraction of $54 \%$ (Figure 1D). There was a tortuous aortic arch with

*Corresponding authors: Giselle Rowlinson, Royal Brompton and Harefield NHS Foundation Trust, Sydney Street, London SW3 6NP, UK, Tel: 004402073528121; E-mail: G.Rowlinson@rbht.nhs.uk

Inga Voges, Royal Brompton and Harefield NHS Foundation Trust, Sydney Street, London SW3 6NP, UK, Tel: 004402073528121; E-mail: i.voges2@rbht.nhs.uk

Received April 22, 2017; Accepted April 25, 2017; Published April 28, 2017

Citation: Rowlinson G, Shore DF, Mireskandari M, Cheshire NJ, Rigby M, et al. (2017) Hybrid Treatment of Multilevel Aortic Disease in an Adolescent: A Case Report. J Cardiovasc Dis Diagn 5: 270. doi: 10.4172/2329-9517.1000270

Copyright: (c) 2017 Rowlinson G, et al. This is an open-access article distributed under the terms of the Creative Commons Attribution License, which permits unrestricted use, distribution, and reproduction in any medium, provided the original author and source are credited. 
Citation: Rowlinson G, Shore DF, Mireskandari M, Cheshire NJ, Rigby M, et al. (2017) Hybrid Treatment of Multilevel Aortic Disease in an Adolescent: A Case Report. J Cardiovasc Dis Diagn 5: 270. doi: 10.4172/2329-9517.1000270

Page 2 of 2

severe narrowing at the aortic isthmus (Figures 2A-2C). Furthermore, the right subclavian artery had an aberrant origin and was arising together with the left subclavian artery at the coarctation site. CMR cine imaging and contrast enhanced magnetic resonance angiography showed high suspicion of origin stenoses of both subclavian arteries (Figures 2B and 2D).

The patient first underwent a hybrid procedure to manage the aortic coarctation. Due to the proximity of both subclavian arteries to the coarctation site he first had bilateral carotid-subclavian Dacron bypass grafting followed by stenting of the aortic coarctation. A $45 \mathrm{~mm}$ covered Cheatham Platinum stent was deployed using an $18 \mathrm{~mm} \times 5 \mathrm{~cm}$ BIB balloon via the right femoral artery. Three weeks later he underwent surgical aortic root replacement. At surgery marked aneurysmal dilatation of the ascending aorta was observed which assumed a normal calibre $2 \mathrm{~cm}$ proximal to the origin of the right carotid artery. The aortic valve was bicuspid with left and right commissures and a rudimentary anterior commissure. The coronaries arteries were excised with buttons of aortic wall and a modified Bentall procedure was performed using a $27 \mathrm{~mm}$ composite St Jude valve and graft.

At $3^{\text {rd }}$ month follow-up the patient no longer complained of nausea and exercise tolerance was normalising. His right arm blood pressure was 105/70 mmHg. A repeat CMR scan showed normalisation of left ventricular size and improved left ventricular function with EF of $61 \%$
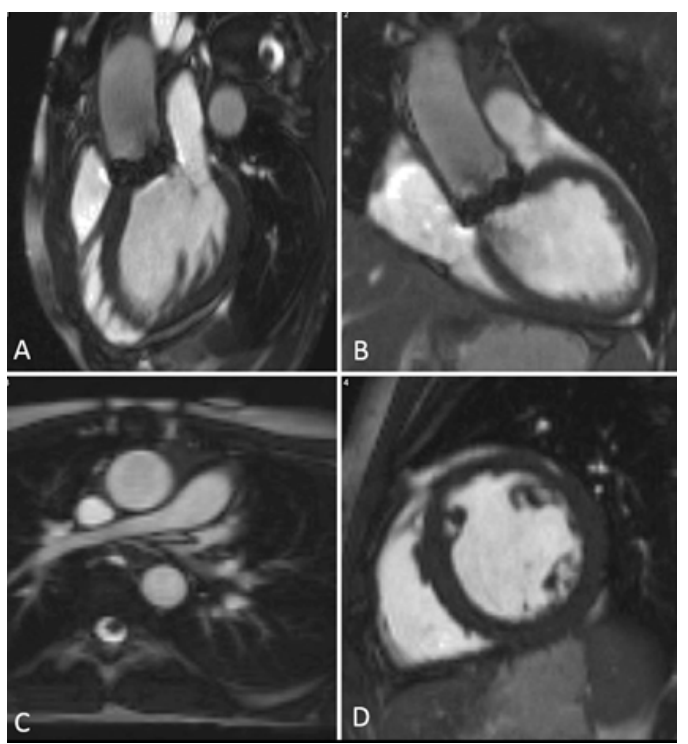

Figure 3: $(A-C)$. Postoperative $C M R$ cine images demonstrating a well seated aortic prosthetic valve and aortic conduit Reduced left ventricular size postoperatively. (D) With improved left ventricular systolic function (LVEF 61\%).

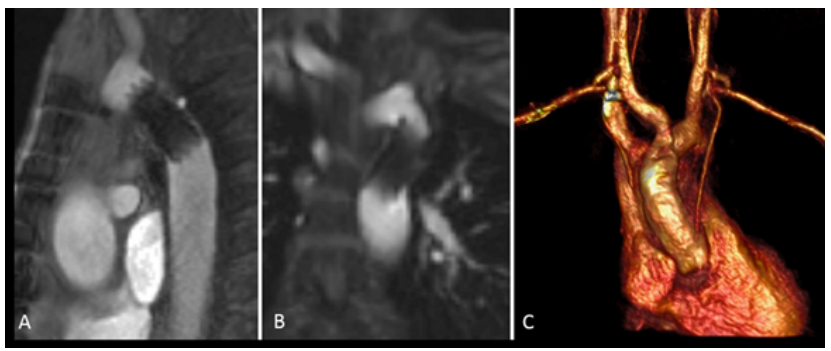

Figure 4: $(A, B)$. CMR cine images and volume-rendered $3 D$ reconstruction showing the stented coarctation. (C). The bilateral Dacron bypass between the carotid and subclavian arteries.
(Figure 3D). The aortic prosthesis was nicely seated and the aortic conduit non-dilated (Figures 3A-3C). In addition, the coarctation stent was non-stenosed and in good position, and both carotid-subclavian Dacron grafts were patent (Figures 4A-4C).

\section{Discussion}

This was an unusual and late presentation in a teenage boy of bicuspid aortic valve disease and complex coarctation of the aorta with associated LV dysfunction. The symptoms of nausea and vomiting were not attributed to an underlying cardiac cause and the chest pains and exercise intolerance had been misdiagnosed as asthma. An ascending aorta diameter of $6 \mathrm{~cm}$ at presentation led to the need for prompt intervention. Two surgery-only options were considered: 1) surgical repair of coarctation followed by aortic root and ascending aorta replacement, 2) aortic root and ascending aorta replacement along with an ascending-to-descending aortic graft. Isolated coarctation stenting followed by the Bentall procedure would have been considered, however there was concern that the aberrant right subclavian and left subclavian arteries would be jailed by a covered stent. Finally, after discussions between congenital cardiologists, interventional cardiologists, cardiac surgeons and vascular surgeons the described hybrid two-stage technique was chosen.

\section{Conclusion}

An individualised management plan was made for this young patient based on the risk-benefits of each approach and according to the expertise available in the specialist hospital. Following the interventions a good anatomical and physiological result has been achieved along with normalisation of ventricular function.

\section{References}

1. Braverman AC, Guven H, Beardslee MA, Makan M, Kates A, et al. (2005) The bicuspid aortic valve. Curr Probl Cardiol. 30: 470-522.

2. ACCF/AHA/AATS/ACR/ASA/SCA/SCAI/SIR/STS/SVM (2010) Guidelines for the diagnosis and management of patients with thoracic aortic disease Representative Members., Hiratzka LF, Creager MA, Isselbacher EM, Svensson LG.

3. AHA/ACC (2014) Guidelines for the management of patients with valvular heart disease Representative Members., Nishimura RA, Bonow RO, Guyton RA Sundt TM. J Thorac Cardiovasc.

4. AHA/ACC (2016) Surgery of aortic dilatation in patients with bicuspid aortic valves: A statement of clarification from the American College of Cardiology/ American Heart Association Task Force on Clinical Practice Guidelines. J Thorac Cardiovasc. 151: 959-966.

5. Massih TA, Vouhe PR, Mauriat P, Mousseaux E, Sidi D, et al. (2002) Replacement of the ascending aorta in children: A series of fourteen patients. $J$ Thorac Cardiovasc Surg 124: 411-413.

6. Varrica A, Satriano A, De Vincentiis C, Biondi A, Trimarchi S, et al. (2014) Bentall operation in 375 patients: Long-term results and predictors of death. $J$ Heart Valve Dis 23:127-134.

7. Wilson W, Osten M, Benson L, Horlick E (2014) Evolving trends in interventional cardiology: Endovascular options for congenital disease in adults. Can $\mathrm{J}$ Cardiol 30: 75-86. 